\title{
LA COMISIÓN INTERNACIONAL CONTRA LA IMPUNIDAD EN GUATEMALA (CICIG). UNA ORGANIZACIÓN AUTORIDIGIDA
}

\author{
THE INTERNATIONAL COMMISSION \\ AGAINST IMPUNITY IN GUATEMALA (CICIG). \\ A SELF-DIRECTED ORGANIZATION \\ LA COMMISSION INTERNATIONALE \\ CONTRE L'IMPUNITÉ AU GUATEMALA (CICIG). \\ UNE ORGANISATION INDÉPENDANTE
}

\section{LAURA Zamudio GonZÁlez Universidad Iberoamericana laura.zamudio@ibero.mx}

Resumen: No pocos de los estudios sobre organizaciones internacionales intergubernamentales (oIs) descartan que éstas sean autónomas o sean capaces de autodirigir sus procesos de cambio. El caso de la Comisión Internacional contra la Impunidad en Guatemala (CICIG) permite precisamente observar en qué grado es autónoma una oi. Mediante el análisis documental y entrevistas con la dirigencia de la cicig, este artículo demuestra que la organización ajustó y reinterpretó su mandato como resultado de un proceso de decisiones internas y autónomas. Esta evidencia contribuye al debate sobre las ors en cuanto actores autodirigidos.

Palabras clave: Corrupción, impunidad, autonomía, actor autodirigido, Estado de derecho.

Abstract: Many studies on international intergovernmental organizations (IOs) rule out there being autonomous or capable of self-directing their processes of change. The case of the International Commission against Impunity in Guatemala (CICIG) makes it possible precisely to observe to what degree an Io is autonomous. Through documentary analysis and interviews with the leadership of the CICIG, this article shows that the organization adjusted and reinterpreted its mandate as the result of a process of internal and autonomous 
decisions. This evidence contributes to the debate about Ios as self-directed actors.

Keywords: Corruption, impunity, autonomy, self-directed actor, rule of law. Traducción de Gonzalo Celorio Morayta

Résumé: D'assez nombreux travaux sur les organisations intergouvernementales (OIG) mènent à croire qu'elles puissent être autonomes ou capables de diriger elles-mêmes leurs processus de changement. Le cas de la Commission internationale contre l'impunité au Guatemala (CICIG) est justement un exemple d'autonomie. L'analyse documentaire et plusieurs enquêtes menées auprès des dirigeants de cette organisation nous permettent de dire que celle-ci a adapté et réinterprété son mandat au moyen de décisions internes et autonomes. L'évidence présentée ici pourrait contribuer au débat concernant les acteurs indépendants.

Mots clefs: Corruption, impunité, autonomie, acteur indépendant, État de droit.

Traducción de BERNARdo Mabire

Fecha de recepción: julio de 2017 Fecha de aceptación: marzo de 2018 
$\mathrm{E}$ L ESTUDIO RECIENTE de las Organizaciones Internacionales Intergubernamentales (oIs) a la luz de las Relaciones Internacionales ha suscitado un debate teórico muy interesante centrado en cuestiones de autonomía y agencia, donde lo que interesa comprender es si, pese a ser una creación de los Estados, algunas ois pueden seguir cursos de acción con base en sus propios intereses y preferencias. Es fundamental estudiar también, como parte de ese debate, si dichas capacidades de agencia podrían, en determinadas circunstancias, afectar las decisiones, intereses y/o identidades de los Estados que las crearon. ${ }^{1}$

Evidentemente el debate ha trazado una línea divisoria entre las aproximaciones teóricas según las cuales, como en los caso del realismo tradicional, el neorrealismo y el neoliberalismo institucional, ${ }^{2}$ argumentan que las ois carecen de acción independiente y sólo importan en cuanto que contribuyen a atender los intereses de los Estados y/o a resolver problemas de acción colectiva o como en el de la teoría cons-

${ }^{1}$ Por organización internacional se entiende "una estructura formal, continua, establecida por acuerdo entre miembros (gubernamentales y/o no gubernamentales) de dos o más Estados soberanos con el propósito de alcanzar un interés común" (C. Archer, International Organizations, Londres-Nueva York, Routledge, 2001, p. 33). Las organizaciones internacionales se consideran un tipo de institución internacional, por lo cual en ocasiones se usan los conceptos de manera indiferenciada. Véase, B. A. Simmons y L. Martin "International Organizations and Institutions", en W. Carlsnaes, T. Risse y B. A. Simmons (eds.), Handbook of International Relations, Londres, SAGE Publications, 2002, pp. 193-211.

${ }^{2}$ R. O. Keohane, After Hegemony: Cooperation and Discord in the World Political Economy, Princeton, University Press, 1984; A. Hasenclever, P. Mayer y V. Rittberger, Theories of International Regimes, Cambridge, University Press, 1997; J. Mearsheimer, "The False Promise of International Institutions", International Security, vol. 19, núm. 3, 1994-95, pp. 5-49; A. Moravcsik, "Taking Preferences Seriously: A Liberal Theory of International Politics", International Organization, vol. 51, núm. 4, 1997, pp. 513-553; K. N. Waltz, Theory of International Politics, Reading, MA, Addison-Wesley Pub. Co., 1979; K. N. Waltz, "Structural Realism after the Cold War", International Security, vol. 25, núm. 1, 2000, pp. 5-41. 
tructivista y Agente-Principal, para la cual en la política mundial actual los Estados no sólo deciden y actúan.

El objetivo de este documento es contribuir al debate mediante el estudio empírico de una or relativamente nueva y exitosa en el combate contra la corrupción, la Comisión Internacional contra la Impunidad en Guatemala (CICIG). La decisión de utilizar este caso de estudio se justifica, precisamente por ser un caso internacionalmente reconocido por muchos, como el de una organización internacional que exhibe altos niveles de autonomía y agencia. Para conceptualizar esta idea de agencia y autonomía, utilizaremos la noción (que ya utilizan algunos internacionalistas) de actor autodirigido, ${ }^{3}$ es decir cuando una organización exhibe capacidad para reinterpretar su mandato y actuar a partir de procesos de decisión endógenos. Esto quiere decir que puede ajustar sus metas y objetivos, asimismo redefinir sus formas de trabajo sin que dichos cambios sean sugeridos o requeridos por los Estados que la financian y/o por las Naciones Unidas que la crearon.

El concepto de actor autodirigido no establece que la autonomía de una organización pueda ser absoluta: ser actor implica tener agencia y tener agencia implica tener siempre restricciones. A propósito de la CICIG, este artículo observará precisamente esa dualidad de la organización como actor: inserta en un origen, en un contexto político particular y con actores estatales e internacionales que la regulan. Fue a partir de una grave crisis para la organización, cuando su existencia estaba siendo cuestionada, que tomó decisiones con base en sus propios intereses de sobrevivencia y generó significados y patrones de acción que no estaban contemplados o no fueron solicitados por sus creadores.

Es un hecho que la CICIG no fue concebida y no nació como una organización para luchar contra la corrupción administrativa. Fue creada para luchar contra la impunidad y el

${ }^{3} \mathrm{~J}$. E. Oestreich (ed.), International Organizations as Self-Directed Actors. A framework for analysis, Nueva York-Londres, Routledge, 2012. 
crimen organizado. Se trata de un cambio sutil, si se quiere, pues corrupción, impunidad y crimen están íntimamente vinculados y resulta difícil trazar fronteras, pero no es un cambio menor, ya que, según se sostiene a lo largo de estas líneas, ello implicó cambiar tres cosas: $i$ ) su objetivo de intervención (a quién perseguir), ii) sus tareas y metodologías (cómo hacerlo) y iii) su estructura organizacional (con qué combinación de recursos), todo sin intervención sustantiva (en contra o para mandatar determinado resultado) de los Estados donantes, el gobierno de Guatemala o funcionarios de las Naciones Unidas. ${ }^{4}$

El cambio de la CICIG implicó también una modificación en sus relaciones externas, específicamente con la sociedad civil de Guatemala, lo que Cox y Jacobson en su taxonomía del proceso de toma de decisiones organizacional llaman boundary decision. ${ }^{5}$

Entonces, no estamos ante una organización que cambió radicalmente y abandonó su razón de ser, ni adquirió una nueva encomienda de Naciones Unidas, del Gobierno de Guatemala o los donantes. Estamos ante una organización que, en un momento histórico determinado, enfrentó fuerte resistencia a su trabajo y graves cuestionamientos sobre su pertinencia y viabilidad $; 6$ percibió el riesgo a su propia exis-

${ }^{4}$ Este artículo sigue el trabajo de Alexander Betts sobre el cambio en el mandato del Alto Comisionado de las Naciones Unidas para los Refugiados (UNHCR, por sus siglas en inglés), donde se define el mandato de una oi como "alcance legítimo de sus actividades" y abarca dos preguntas fundamentales: ¿a quién proteger? y ¿cómo hacerlo? Para el caso de la CICIG, las preguntas que guían el estudio hubieron de adaptarse: ¿a quién perseguir?, ¿cómo hacerlo? y ¿con qué combinación de recursos? Véase Betts, "The United Nations High Commissioner for Refugees: Autonomy and Mandate Change", en J. O. Oestreich (ed.), International Organizations as Self-Directed Actors. A framework for analysis, Nueva York-Londres, Routledge, 2012, pp. 119-140.

5 The Anatomy of Influence. Decision Making in International Organizations, New Haven-Londres, Yale University Press 1973, p. 10.

${ }^{6}$ El presidente de Guatemala Otto Pérez Molina y la vicepresidente Roxana Balderetti endurecieron su posición contra la CICIG; en 2013 y en 
tencia y respondió ajustando sus tareas y encomienda original. El resultado fue exitoso, pues adquirió gran relevancia y legitimidad y, hoy por hoy, se la tiene por un modelo repetible en naciones donde se lucha en contra de la corrupción. ${ }^{7}$

Este proceso de cambio y redefinición interna de la CICIG en torno a su mandato original, constituye pues "una anomalía” para algunas aproximaciones teóricas predominantes en la bibliografía especializada en Relaciones Internacionales, donde el cambio de mandato estaría predominantemente concebido y dirigido por los Estados. Para una buena parte de esta bibliografía, las ois no tienen capacidad para interpretar su contexto y decidir de manera autónoma, de allí que este caso resulte interesante de estudiar, partiendo sobre todo de una perspectiva endógena.

Para comprender las dinámicas de acción y decisión endógenas que llevaron al cambio en la interpretación del mandato, se revisaron planes de trabajo e informes anuales de la CiCIG, así como un proceso de entrevista a los dos más altos mandos de la organización -el actual comisionado, Iván Velásquez Gómez y la directora de investigación, Luz

2014, oponiéndose a la tercera renovación de su mandato, declararon que debía prepararse para transferir sus capacidades a las instituciones de Guatemala. Véase "Una nueva prórroga a la labor de la CICIG", El Siglo, 16 de abril de 2016, en http://s21.gt/2016/04/19/una-nueva-prorroga-a-lalabor-la-cicig.

${ }^{7}$ Un experimento semejante comenzó a hacerse en Honduras (véase Misión de Apoyo contra la Impunidad y la Corrupción en Honduras (мACсін), en http://www.oas.org/es/sap/dsdme/maccih/new/mision. asp., consultado el 5.IX.2016). Distintos medios de opinión manifiestan que el trabajo de la cicig constituye un ejemplo que debería seguirse en muchos otros países de la región. Por ejemplo, véase J. Paullier, "Iván Velásquez, jefe de la Cicig en Guatemala: «No soy responsable de la caída de Pérez Molina»", BBC Mundo, 4 de septiembre de 2015, en http:/ /www. bbc.com/mundo/noticias; A. Arce, "Pese a las amenazas, la fiscal general de Guatemala, Thelma Aldana, afirma que su trabajo anticorrupción «no ha terminado"”, The New York Times, 30 de septiembre de 2016; J. García, "Cárcel para tres ministros del expresidente de Guatemala por «regalar» un helicóptero”, El País, 13 de junio de 2016, en http://internacional.elpais.com. 
Adriana Camargo- el pasado 30 de marzo, de 2017, en la sede de la cicig, en la Ciudad de Guatemala. Al ser la CICIG una organización que ha logrado llevar a la cárcel a importantes políticos y empresarios de Guatemala, los niveles de seguridad y secrecía con los que actúa requirieron de la investigación presente desarrollar un proceso cuidadoso de negociación que duró seis meses y la ejecución de entrevistas bajo estrictos controles de seguridad y sin instrumentos de grabación. Ambas entrevistas fueron desarrolladas in situ en las oficinas de la organización y su duración fue de aproximadamente 90 minutos cada una. La estructura de las entrevistas siguió tres grandes bloques: $i$ ) el proceso político y organizacional del cambio o ajuste de mandato que vivió la organización, ii) quiénes y cómo tomaron decisiones y iii) los procesos organizacionales internos que se crearon a la luz de ese ajuste. En otras palabras, las entrevistas buscaron indagar sobre los grados de autonomía para ajustar el mandato a las realidades locales y prácticas, así como los procesos decisorios que internamente se generaron para sostener el mandato en la acción diaria de toda la organización. No fue posible realizar más entrevistas al personal de la cICIG, pues el control de la información es muy estricto. Sin embargo, la entrevista a los dos individuos que toman las decisiones más importantes de la cicig ayudó a encontrar cierto tipo de evidencia de cómo los propios actores organizacionales interpretan los niveles de autonomía de decisión que utilizaron y alcanzaron.

El presente artículo cuenta con dos apartados. El primero establece una definición operativa de los conceptos de autonomía y agencia en las ors, utilizando los estudios de las Relaciones Internacionales que, partiendo de las posiciones de la teoría constructivista y de la teoría Agente-Principal, han comenzado a abrir "la caja negra" de las decisiones de las ors y las perciben como actores autodirigidos. El segundo apartado, analiza el caso de la cicig con dos hilos conductores: $i$ ) el cambio en la interpretación del mandato (observable a partir del cambio en cuanto al sujeto que se persigue, 
las tareas o maneras de perseguirlos y la estructura organizacional o combinación de recursos) y ii) los factores que contribuyeron al desarrollo de este proceso desde una perspectiva endógena y autodirigida. Por último, se presentan algunas reflexiones a modo de conclusión sobre la importancia de estudiar cómo y de qué manera ciertas ois adquieren y usan diversos grados de autonomía para el desarrollo de sus objetivos.

\section{El Debate teórico SObre Autonomía y Agencia EN ORganizaciones INTERNACIONALES}

Todas las aproximaciones teóricas desde la disciplina de las Relaciones Internacionales aceptan que las oIs existen de manera independiente a los Estados. Éstas tienen sede, emblema, personal contratado, cartas constitutivas y presupuestos específicos que, en la mayoría de los casos, provienen de los Estados que las crearon. Sin embargo, son todavía pocas las posturas que aceptan la posibilidad de que las ois ejerzan una acción autónoma y significativa. ${ }^{8}$

Concebir las oIs como actores con autonomía implica mucho más que aceptar su existencia independiente. ${ }^{9}$ En el

${ }^{8}$ De M. Barnett y M. Finnemore, cf. "The Politics, Power and Pathologies of International Organizations”, International Organization, vol. 53, núm. 4, 1999, pp. 699-732, y Rules for the World: International Organizations and Global Politics, Ithaca-Londres, Cornell University Press, 2004. También véanse Randy Hodson et al., "Rules don't apply: Kafka's insigths on burocracy”, Organization, vol. 22, núm. 2, 2012, pp. 256-278; Oestreich, ed. cit.; B. Reinalda y B. Verbeek, Autonomous policy making by International Organizations, Nueva York-Londres, Routledge, 1998; Reinalda y Verbeek (eds.), Decision Making Within International Organizations, pref. de R. W. Cox, Nueva York-Londres, Routledge, 2004.

${ }^{9}$ El concepto de autonomía en or no está perfectamente definido, mucho menos consensuado. Si bien se acepta que constituye un concepto multidimensional, estudiosos como David Lake y Methew McCubbins señalan la definición de una agenda y la posibilidad de no rendir cuentas como elementos fundamentales en la variabilidad de la autonomía orga- 
fondo, se requiere de un cambio ontológico, es decir rechazar su concepción como instancias pasivas que carecen de intereses y propósitos, confinadas a ser mecanismos para la acción y/o manipulación de otros. ${ }^{10} \mathrm{Y}$ ello no es fácil para una disciplina que se mueve bajo un paradigma estado céntrico. No es casual que la bibliografía que concibe las ois como actores significativos esté limitada y se encuentre ubicada mayormente fuera de la disciplina. ${ }^{11}$ A la luz de las Relaciones Internacionales, las teorías que podrían posibilitar un acercamiento más sofisticado al debate sobre autonomía y agencia son el constructivismo (desde una interpretación burocrática weberiana), de raíz sociológica y, la teoría agente-principal, de raíz económica. ${ }^{12}$ Estas dos grandes teorías han sido utilizadas de diversas maneras y en diversos contextos tanto en la sociología, como en la economía, la ciencia política y las Relaciones Internacionales. Aquí recuperaremos precisamente la bibliografía que desde las Relaciones Inter-

nizacional ("The Logic of Delegation to International Organizations", en D. Hawkins, D. Lake, D. Nielson y M. J. Tierney, eds., Delegation and Agency in International Organizations, Nueva York-Cambridge, Palgrave Macmillan, 2006, pp. 241-368). Para otros, la autonomía está vinculada a la capacidad de tomar decisiones de manera independiente, sin interferencia de los Estados que la constituyeron. Cf. R. Collins Richard y N. D. White, International Organizations and the Idea of Autonomy. Institutional Independence in the Legal Order, Londres-Nueva York, Routledge, 2011.

${ }^{10}$ D. Ellis, "The Organizational Turn in International Organizations Theory", Journal of International Organizations Studies, vol. 1, núm.1, 2010, pp. 1-18.

${ }^{11}$ Fuera de la disciplina de Relaciones Internacionales hay un conjunto de bibliografía especializada que proviene de la teoría de las organizaciones e incide fuertemente en el estudio de las ois como organizaciones, es decir con autonomía y agencia específicas. Véase J. Trondal et al., Unpacking International Organizations. The Dynamics of Compound Bureaucracies, Manchester, University Press, 2010; G. Ahrne y N. Brunsson, Meta-organizations, Cheltenham, UK-Northampton, MA, Edward Elgar Publishing, 2008; Reinalda y Verbeek (eds.), Decision Making...

${ }^{12}$ Barnett y Finnemore, art. cit. y op. cit.; D. G. Hawkins et al. (eds.), Delegation and Agency in International Organizations, Nueva York, Cambridge University Press, 2004. 
nacionales está comenzando a estudiar las ois y sus capacidades de decisión y agencia tomando como base tosas esas grandes teorías.

Cierto es que las teorías Agente-Principal y burocrática weberiana nacen en otras disciplinas, pero cada vez más se están usando para comprender las organizaciones internacionales intergubernamentales. Representan un cruce interdisciplinario todavía poco desarrollado empíricamente, pero interesante, porque está posibilitando la investigación a favor del análisis endógeno y con miras a comprender la variación en sus respuestas -en ocasiones exitosas y a veces verdaderos desastres. Estos trabajos se preguntan, por ejemplo, ¿por qué las organizaciones internacionales exhiben comportamientos disfuncionales y hasta patológicos? ¿Qué las hace organizacionalmente más débiles en materia de regulación que las organizaciones estatales? ¿Qué tanto sus propios intereses y agenda las desvía de su mandato? ${ }^{13}$

La teoría constructivista enfatiza la importancia que tienen las ideas, reglas y normas en el comportamiento de los Estados. ${ }^{14}$ El supuesto más importante sobre el Estado es que

${ }^{13}$ Barnett y Finnemore, art. cit. y op. cit.; D. Dijkzeul e Y. Beigbeder, Rethinking International Organizations. Pathology and Promise, Nueva York, Bergahn Books, 2003; Reinalda (ed.), Routledge Handbook of International Organization, Londres-Nueva York, Routledge, 2013; Reinalda y Verbeek (eds.), Decision Making...; Reinalda y Verbeek (eds.), Autonomous Policy Making...; J. d'Aspremount, "The Multifaceted Concept to of Autonomy of International Organizations and International Legal Discourse", en R. Collins y N. D. White, International Organizations and The Idea of Autonomy, Londres, Routledge, 2011; K. V. Bryant, "Agency and Autonomy in International Organizations: Political Control and the Effectiveness of Multilateral Aid", San Francisco, Annual Convention of the American Political Science, 2015; 29th Joint Sessions of Workshops, Grenoble, Francia, 6-11 de abril de 2001.

${ }^{14}$ A. Wendt, "Anarchy is what States Make of it: The Social Construction of Power Politics", International Organization, vol. 46, núm 2, 1992, pp. 391-425; T. Hopf, "The promise of Constructivism in International Relations Theory", International Security, vol. 23, núm. 1, pp. 171-200; J. T. Checkel, "The Constructivism Turn in International Relations Theory", World Politics, vol. 50, núm. 2, pp. 324-348. 
no es un actor racional, es decir que toma decisiones con base en cálculo costo-beneficio y persigue intereses fijos previamente definidos. Antes bien, es un actor que toma decisiones con base en roles y papeles acordes a su identidad. ${ }^{15}$ Los Estados no están solos ni aislados, pues se mueven en contextos de interacción-aprendizaje y restricciones normativas e institucionales, por lo que sus intereses, preferencias e identidades cambian.

El estudio sobre las oIs y su comportamiento está, en efecto, poco desarrollado. Sin embargo, recientemente se ha venido elaborando un argumento interesante sobre la acción de las ois que parte del constructivismo y la teoría burocrática weberiana. Barnett y Finnemore, conocidos representantes de esta argumentación, sostienen que "las organizaciones internacionales pueden convertirse en sitios autónomos de autoridad, independientes de los Estados, a partir del poder derivado de $i$ ) la autoridad de la racionalidad-legal que las constituye y ii) el control burocrático sobre la información y experiencia técnica”. ${ }^{16}$

Así, las oIs no solamente facilitan la cooperación entre Estados -resolviendo fallas de mercado o problemas de acción colectiva-, como sostiene el neoliberalismo institucional, sino que crean actores y nuevos entendimientos de la realidad; definen responsabilidades y relaciones de autoridad; establecen formas de acción y brindan sentido normativo a las acciones de los actores. ${ }^{17}$ Las reglas, normas y rutinas definidas por las organizaciones establecen los parámetros

15 Esta teoría establece que las normas y las identidades, además de ser mutuamente constitutivas, se van modificando como resultado de su interacción. Cf. M. Finnemore y K. Sikkink, "Taking Stock: The Constructivist Research Program in International Relations and Comparative Politics”, Annual Review of Political Science, vol. 4, núm.1, 2001, pp. 391-416.

16 Art. cit., p. 707.

17 A. Johnston, "Treating International Institutions and Social Environments”, International Studies Quarterly, vol. 45, núm. 4, 2001, pp. 487515; Finnemore y Sikkink, "International Norm Dynamics and Political Change”, International Organization, vol. 52, núm. 4, 1988, pp. 887-917. 
de acción y estándares de comportamiento esperados por parte de los Estados, como sucede, por ejemplo, con la atención a refugiados o apátridas (Alto Comisionado de Naciones Unidas para Refugiados), a más de resolver problemas comerciales (Organización Mundial de Comercio) o castigar el genocidio y los crímenes en contra de la humanidad (Corte Penal Internacional).

Desde esta perspectiva, las ois tienen poder y lo usan para crear actores, significados, intereses, categorías sociales y cursos de acción. Reiteran que no se trata de un poder conferido u otorgado por los Estados, sino de un poder que deriva de su autoridad racional (de reglas impersonales) y de su conocimiento experto o, en otras palabras, de su propia naturaleza burocrática. La autonomía que fluye de estas dos condiciones burocráticas es entonces una característica inherente y constitutiva. $^{18}$

Así pues, las ois toman decisiones abstrayéndose del contexto y aislándose de los Estados y apegándose a reglas, rutinas y culturas organizacionales. ${ }^{19}$ Las burocracias internacionales ordenan, regulan y simplifican sus contextos mediante reglas, conceptos y procedimientos de acción y, con base en esas reglas y procedimientos, toman decisiones y ejercen su poder. Sin embargo, irónicamente la racionalidad legal las lleva también a ser disfuncionales o tomar decisiones que rayan en patologías, apegándose al cumplimiento de la regla, por sobre cualquier otra racionalidad. ${ }^{20}$

En este documento, por tanto, la teoría constructivista se analiza solamente desde la perspectiva sociológica weberiana, en que las decisiones están permeadas por la cultura organizacional burocrática. No se analizan otras interpretaciones que dan cuenta del valor de las normas y la socialización de las mismas fuera de los actores organizacionales o que explí-

18 Barnett y Finnemore, art. cit., p. 707.

19 Ibidem, p. 706.

20 Ibid., p. 715. 
citamente establecen el cambio que provocan las normas e ideas en las identidades estatales.

Desde el ámbito económico, la teoría Agente-Principal advierte también algunos espacios de autonomía. ${ }^{21}$ Esta teoría sostiene que los Agentes (en este caso, ors) son contratados por los Principales (en este caso, Estados) para realizar algunas funciones que los Estados por sí mismos no pueden realizar o resultan muy costosas, cuando falta una instancia de coordinación. ${ }^{22}$ Mediante un "contrato", los Principales delegan autoridad a los agentes, estipulan las tareas generales por realizar e introducen mecanismos de vigilancia y supervisión sobre el Agente. Sin embargo, nada de ello está perfectamente definido o contemplado, pues ni el Principal o principales suelen tener perfectamente claro lo que quieren, ni pueden estipular las tareas y acciones de cada día para lograrlo. Tampoco es posible establecer mecanismos de vigilancia y supervisión que contemplen todas las posibles desviaciones del Agente. A esto hay que sumar el hecho de que los intereses del Agente y del Principal no siempre coinciden. ${ }^{23}$

Las posibilidades de acción autónoma derivan, entonces, de una idea más sofisticada e interesante, pues se reconoce explícitamente que los Agentes tienen sus propios intereses y siguen su propia agenda. El supuesto fundamental sobre las ois es que, en su accionar, buscarán aumentar sus presupuestos, sus tareas, su relevancia e impacto en el contexto, la seguridad de su personal, así como, en casos extremos, su sobrevivencia como organización. ${ }^{24}$ Toda vez que los intere-

${ }^{21}$ Hawkings et al., ed. cit.

${ }^{22}$ Hawkings et al., "Delegation Under Anarchy: States, International Organizations and Principal-Agent Theory", en D. G. Hawkings, D. A. Lake, D. L. Nielson y M. Tierney (eds), Delegation and Agency in International Organizations, Nueva York, Cambridge University Press, 2004, pp. 3-37.

${ }^{23}$ M. Pollack, "Delegation, Agency, and Agenda-Setting in the European Community", International Organization, vol. 51, núm. 1, 1997, pp. 99-134.

${ }^{24}$ Un ejemplo de sobrevivencia organizacional fue el genocidio en Ruanda (1994), donde las Naciones Unidas optaron por retirarse y evitar 
ses de los Principales y los Agentes no siempre coinciden, éstos intentarán incluso explotar las asimetrías de información, preferencias heterogéneas de los principales y liderazgo organizacional para ejercer y, de ser posible, ampliar sus márgenes de acción independiente y autónoma. Con el tiempo, las oIs llegarán incluso a cambiar sus tareas, funciones y áreas de responsabilidad, advirtiendo un proceso de evolución y madurez a favor de mayor fortaleza y autonomía. ${ }^{25} \mathrm{De}$ ello, un ejemplo interesante es el Alto Comisionado de las Naciones Unidas para los Refugiados (ACNUR) que se ideó para vivir tres años, con un presupuesto reducido y con la misión de atender solamente a los refugiados europeos, aunque hoy sea la organización más importante mundialmente.

Una observación que se desprende del análisis AgentePrincipal es que organizaciones grandes, complejas y maduras podrían tener mayor autonomía a causa de los mecanismos de supervisión impuestos por los Principales, que son más difíciles y costosos de implementar, y/o porque, con el tiempo, los Agentes han ampliado sus tareas y fortalecido sus culturas organizacionales. Por el contrario, una oi pequeña (por el tamaño de su equipo de trabajo o por el número de Principales) tendrá menos posibilidad de acción autónoma, porque los mecanismos de supervisión impuestos por los Principales pue-

un segundo descalabro internacional, como los ocurridos meses antes en Somalia, con lo cual se desviaron por completo de su misión y propósitos originales, además de permitir la perpetración de un genocidio. Veáse Barnett y Finnemore, "Genocide and the Peacekeeping Culture at the United Nations", en Rules for the World. International Organizations in Global Politics, Ithaca-Londres, Cornell University Press, 2004, pp. 121-156; R. Dallaire, Shake Hands with the Devil. The Failure of Humanitary in Rwanda, Nueva York, Carroll and Graf Publishers, 2003.

25 Para evidencia empírica sobre este punto, veáse Barnett y Finnemore, "Defining Refugees and Voluntary Repatriation at the United Nations High Commissioner for Refugees", en Rules for the World. International Organization in Global Politics, Ithaca-Londres, Cornell University Press, 2004, pp. 73-121; Oestreich, "UNICEF and the Implementation of the Convention on the Rights of the Child", Global Governance, vol. 4, núm. 2, 1998, pp. 183-199. 
den ser mucho menos costosos y más efectivos, ${ }^{26}$ lo cual, según se verá en el caso analizado, no siempre ocurre de ese modo.

En suma, no hay en realidad una teoría general sobre la autonomía y la agencia de las ois según la disciplina de las Relaciones Internacionales. Sin embargo, la conceptualización de las organizaciones como actores autodirigidos permite trazar una definición operativa y preliminar que deriva de los supuestos anteriormente expuestos. Según los argumentos de constructivismo y teoría Agente-Principal, una or tendrá autonomía cuando $i$ ) sea capaz de tomar decisiones de manera endógena, atendiendo sus intereses, reglas y procedimientos sin intervención directa de los Estados que la crearon o "contrataron" y ii) cuando tenga la capacidad de definir nuevos conceptos, actores y significados de la realidad social, ampliando sus tareas y márgenes de acción.

Por supuesto que se trata de una definición operativa y preliminar, pero introduce una nueva agenda de investigación. Académicos de Relaciones Internacionales están comenzando a cuestionarse seriamente sobre el funcionamiento y naturaleza de las oIs, convencidos de que estas estructuras juegan un papel cada vez más relevante en la gobernanza internacional. ${ }^{27} \mathrm{El}$ análisis de casos y evidencia empírica vienen a contribuir a este debate.

\section{ESTUDIO DE CASO: LA CICIG}

La Comisión Internacional contra la Impunidad en Guatemala (CICIG) es hoy día un mecanismo internacional suma-

${ }^{26}$ Pollack, art. cit. Un ejemplo de sobrevivencia organizacional fue el genocidio en Ruanda.

${ }^{27}$ I. Hurd, International Organizations, Politics, Law, Practice, Nueva York, Cambridge University Press, 2011; M. Karns y K. Mingst, International Organizations: The Politics and Processes of Global Governance, Boulder, CO, Lynne Rienner Publishers, 2004; P. Diehl y B. Frederking (eds.), The Politics of Global Governance: International Organizations in an Interdependent World, Boulder, CO, Lynne Rienner Publishers, 2005. 
mente novedoso y sui generis en materia de combate a la corrupción. ${ }^{28}$ Fue creada por la Organización de las Naciones Unidas (ONU) en 2006 y ratificada por el Congreso de Guatemala en 2007 como parte de los acuerdos de paz, en particular del Acuerdo Global sobre Derechos Humanos, con la intención de "apoyar, fortalecer y coadyuvar a las instituciones del Estado de Guatemala a investigar, perseguir y desarticular cuerpos ilegales y aparatos clandestinos de seguridad que cometen delitos y afectan los derechos humanos fundamentales de los ciudadanos" ${ }^{29}$

Los llamados cuerpos ilegales y aparatos clandestinos de seguridad (CIACS), creados por el propio gobierno durante la Guerra Civil (1960-1996) para hacer frente a la guerrilla, no fueron desmantelados durante el periodo posconflicto, lo cual provocó altas tasas de criminalidad e impunidad. La tasa de homicidio, por ejemplo, pasó de 25.9 por 100000 en el año 2000 a 39.9 por cada 100000 en 2012 (cuando el promedio mundial era de 6.2 por cada 100000$),{ }^{30}$ mientras que el nivel de impunidad en 2007 llegó al 98\%.31 Estos altos niveles de violencia y criminalidad fueron denunciados reiteradamente por organizaciones de la sociedad civil nacional e internacional y defensores de derechos humanos, para quienes el problema central de Guatemala era la debilidad del

${ }^{28}$ Entrevista de la autora a Iván Velásquez Gómez, Comisionado de la Cicig, Ciudad de Guatemala, 30 de marzo de 2017. Adviértase, en lo sucesivo, que a esta fuente remiten todas las citas y referencias que se hagan de Velásquez Gómez en el artículo, por lo cual no será necesario repetir una vez más los datos de la entrevista. Lo mismo vale para la que se hizo a Luz Adriana Camargo, que ha de citarse por completo más adelante.

${ }^{29}$ CICIG, "Acuerdo entre la Organización de las Naciones Unidas y el Gobierno de Guatemala relativo al establecimiento de la Comisión Internacional contra la Impunidad en Guatemala (CICIG)", 12 de diciembre de 2006.

${ }^{30}$ United Nations Office on Drug and Crime, "Global Study on Homicide", 2013, en http://www.unodc.org.

${ }^{31}$ C. Castresana, "Guatemala. Illegal Entities and the Clandestine Security Apparatus", en M. Diezdzic (ed.), Criminalized Power Structures. The Overlooked Enemies of Peace, Nueva York, Rowman-Littlefield, 2016, p. 65. 
Estado y, por consiguiente, la incapacidad de sus instituciones para evitar ser capturados por estructuras criminalizadas. El problema persistió durante diversas administraciones presidenciales hasta que, en 2003, diversas organizaciones de la sociedad civil lanzaron una campaña de presión para que el gobierno solicitara apoyo de Naciones Unidas a favor de un mecanismo de investigación y apoyo.

Naciones Unidas venía insistiendo entonces en la importancia de fortalecer el Estado de Derecho en contextos posconflicto. Diversos comunicados del Secretario General de la organización llamaban a que se interviniera "allí donde las autoridades domésticas no quieren o no pueden perseguir a los violadores de derechos humanos" 32 o donde "emerjan nuevas amenazas al Estado de derecho como el crimen organizado y el tráfico ilícito". ${ }^{33}$ Desde la década de los noventa, Agenda para la $\mathrm{Paz}^{34}$ posibilitó un legado de instituciones e instrumentos dirigidos a consolidar procesos de pacificación en contextos posconflicto, como los tribunales penales internacionales ad hoc (Ruanda y la otrora Yugoslavia) y los tribunales "mixtos o híbridos" (Timor Oriental, Sierra Leona, Camboya y Líbano), que sustituyen y/o complementan los sistemas de justicia locales, así como comisiones para la verdad, comisiones de investigación, asistencia técnica y, en casos extraordinarios, instauración de Administraciones de transición (Timor Oriental y Kosovo).

La CICIG vino a sumarse a este amplio repertorio de instituciones posconflicto, pero con una problemática y un di-

${ }^{32}$ Reporte del Secretario General de las Naciones Unidas ante el Consejo de Seguridad, "The Rule of Law and Transitional Justice in Conflict and Posconflict Societies", S/2004/616, 23 de agosto de 2004, pp. 1-24.

${ }^{33}$ Reporte del Secretario General de las Naciones Unidas ante el Consejo de Seguridad, "The Rule of Law and Transitional Justice in Conflict and Posconflict Societies”, S/2011/634, 12 de octubre de 2011, pp. 1-19.

${ }^{34}$ B. Boutros-Ghali, "Agenda para la paz. Diplomacia preventiva, establecimiento de paz y reconstrucción de paz”, A/47/277, S2411, Memoria del Secretario General sobre la labor de la organización, 17 de junio de 1992, en http://www.un.org. 
seño diferentes, ya que si bien funciona con una combinación de recursos nacionales e internacionales, como las cortes híbridas, no pretende castigar, a la inversa de éstas, a quienes cometieron crímenes graves durante los conflictos armados. En estricto sentido, la CICIG acompaña procesos de investigación y persecución criminal. ${ }^{35}$ Fiscales internacionales trabajan en el país con sus propias leyes y en apoyo al Ministerio Público, la Policía Nacional Civil y otras instituciones del Estado. Su peculiaridad radica en que impulsa el fortalecimiento del sistema de justicia local desde dentro del país, trabajando con las leyes e instituciones nacionales "sin pretender sustituir o reemplazar sus instituciones de gobierno". ${ }^{36}$

A la inversa de la Comisión de Investigación de Cuerpos Ilegales y Aparatos Clandestinos de Seguridad (cICIACs), que constituyó la primera propuesta de Naciones Unidas en Guatemala, dotada de capacidad de investigación y persecución independientes, la CICIG tiene un mandato mucho más limitado, toda vez que posee capacidad de investigación independiente, pero está obligada a presentar todos sus casos al Ministerio Público, funcionando bajo los principios de complementariedad y acompañamiento (o, según se indica, querellante adhesivo). No posee capacidad de fiscalía y persecución independientes, pues, como estableció la Corte de Constitucionalidad de Guatemala, esos poderes corresponden solamente al Ministerio Público.

De conformidad con su mandato, la cICIG tiene tres objetivos principales:

1) Investigar la existencia de Cuerpos Ilegales y Aparatos Clandestinos de Seguridad que cometen delitos y afec-

35 A. Hudson y A. W. Taylor, "The International Commission against Impunity in Guatemala: A New Model for International Criminal Justice Mechanisms", Journal of International Criminal Justice, vol. 8, núm. 1, 2010, pp. 53-74; S. Nouwen, "Hybrid Courts. The Hybrid Category of a New Type of International Crimes Courts", Utrecht Law Review, vol. 2, núm. 2, 2006, en http://www.utrechtlawreview.org.

36 Corte de Constitucionalidad, Guatemala, "Opinión consultiva”, expediente núm. 1250-2004, 5 de agosto de 2004. 
tan los derechos humanos fundamentales de los ciudadanos de Guatemala e identificar las estructuras de estos grupos ilegales (incluidos sus vínculos con funcionarios del Estado), actividades, modalidades de operación y fuentes de financiación.

2) Colaborar con el Estado en la desarticulación de los aparatos clandestinos de seguridad y cuerpos ilegales de seguridad y promover la investigación, persecución penal y sanción de los delitos cometidos por sus integrantes.

3) Hacer recomendaciones al Estado de Guatemala para la adopción de políticas públicas destinadas a erradicar los aparatos clandestinos y cuerpos ilegales de seguridad y prevenir su reaparición, incluidas las reformas jurídicas e institucionales necesarias para este fin.

Se entiende por Cuerpos Ilegales de seguridad y Aparatos Clandestinos de Seguridad aquellos grupos que

a) Cometan acciones ilegales para afectar el pleno goce y ejercicio de los derechos civiles y políticos; y

b) Estén vinculados directa o indirectamente con agentes del Estado o cuenten con capacidad para generar impunidad para sus acciones ilícitas.

De conformidad con su acuerdo de creación, la CICIG tiene diversas facultades o poderes, a saber: $i$ ) investigar a cualquier persona, entidad oficial o privada (Art. 3 1a); ii) promover la persecución penal ante el Ministerio Público de Guatemala y constituirse como querellante adhesivo (Art.3 1b); iii) denunciar a funcionarios y empleados públicos que en el ejercicio de su cargo hayan cometido presuntamente infracciones administrativas o que presuntamente intenten obstaculizar el funcionamiento de la Comisión y participar como tercero interesado en procedimientos disciplinarios (Art.3 1d, e); iv) suscribir e implementar Acuerdos de Cooperación con el Ministerio Público, la Corte Suprema de Justicia, la institución del Procurador de Derechos Humanos, la Policía Nacional Civil y cualesquiera otras instituciones del Estado (Art. 3 1f); v) solicitar declaraciones, documentos, in- 
formes y colaboración en general de cualquier persona o entidad pública o privada (Art. 4, 1).

Además, la CICIG tiene personalidad jurídica y capacidad legal para $i$ ) celebrar contratos, $i i$ ) adquirir y enajenar bienes inmuebles, iii) iniciar procedimientos judiciales y $i v$ ) cualquier otra acción autorizada por la legislación guatemalteca para la realización de sus actividades (Art. 4,1). Investida con estos poderes formales, la CICIG realiza tres funciones sustantivas: $i$ ) investigación, persecución y garantías de no repetición, ii) propuestas de reforma de Política Pública, a partir de informes temáticos definidos por el comisionado y expedición de normas, y iii) propuestas de reforma jurídicas.

En cuanto a su estructura organizacional, la CICIG tiene tres áreas generales y dos departamentos: la Oficina del Comisionado (en la cual se reúne un equipo de apoyo técnico y ejecutivo), el área política (donde se coordina el trabajo de formulación de recomendaciones para elaborar políticas públicas y reformas legislativas) y el área de prensa (responsable de articular la estrategia de comunicación en general). Además, el Departamento de Investigación y Litigio, conformado por las unidades investigativas y las secciones de información y análisis, así como de investigación financiera que acompañan directamente al Ministerio Público y el Departamento de Administración, encargado de prestar apoyo logístico y operativo a sus actividades sustantivas.

El comisionado de la CICIG es designado por el Secretario general de la onu y, tal como establece el Acuerdo de creación, representa a la organización ante el gobierno de Guatemala, así como ante otros Estados y organizaciones locales e internacionales (Art. 5 a:7). En estricto sentido, es el único funcionario de las Naciones Unidas y está obligado a informar anualmente sobre sus actividades mediante de un informe que presenta en Nueva York.

El equipo de la CICIG está integrado por 173 personas procedentes de Argentina, Canadá, Chile, Colombia, Costa Rica, El Salvador, España, Francia, Honduras, Italia, México, Perú, Portugal, Suecia, Uruguay y Venezuela. Además, la Co- 
misión cuenta con apoyo de 70 agentes de la Policía Nacional guatemalteca, los cuales cumplen con funciones de investigación y seguridad e integran una unidad de policía que apoya la Oficina de Fiscalía Especial para la CICIG (UEFAC), que es el vínculo y canal de comunicación directo entre el Ministerio Público y la cicig. Esta unidad se encarga de los arrestos de alto riesgo, intercepción de llamadas telefónicas y seguridad del personal de la CICIG. Comenzó a operar en 2008 y está integrada por cadetes recién egresados de la Academia; reciben un salario $15 \%$ superior al de sus pares; se concentran en un espacio físico especial y se someten a detección de bolígrafo de manera mensual para evitar infiltración.

La CICIG no recibe financiamiento del presupuesto regular de las Naciones Unidas. Todos sus fondos provienen de donaciones voluntarias de diversos países, administradas mediante el Programa de Naciones Unidas para el Desarrollo (PNUD). El grupo de donantes está integrado por Noruega, Alemania, Canadá, España, Estados Unidos, Italia, Japón, Países Bajos y Suecia, así como el Banco Interamericano de Desarrollo, Banco Mundial, Fondo Monetario Internacional, Programa de Naciones Unidas para el Desarrollo, Unión Europea y Organización de Estados Americanos. ${ }^{37}$

El presupuesto original de la CICIG, de conformidad con el PNUD fue de 28890963 dólares norteamericanos y actualmente ronda los 12 millones de dólares, dependiendo de la composición y contribuciones de los países donantes. Esta-

${ }^{37}$ Contribuciones individuales en 2014-2015 en euros: Suecia, 7181 071; Estados Unidos, 6247 560; otros, 6247 560. Contribuciones individuales en 2015-2016: Estados Unidos, 4585894 euros; Suecia, 4127 304; Canadá, 2751 536; Alemania, 1192 332; Países Bajos, 596 166; España, 146 749; Reino Unido, 235 666; y otros, 10915 803. Cf. "Action Fiche for Project to Support the International Commission against Impunity in Guatemala (CICIG)'s Exit Strategy until September 2015", en http:/ /www.europarl.europa.eu, y "Action Document for Support to the Extended Mandate of the International Commission against Impunity in Guatemala (CICIG)”, núm. de CRIS 2016 / 039-237, financiado por Development Cooperation Instrument, en https://ec.europa.eu/europeaid. 
dos Unidos es el mayor contribuyente individual de la CICIG y, desde 2008, ha donado 36 millones de dólares. La Unión Europea en su conjunto donó 4 millones de euros para el periodo 2014-2015 y 5 millones para el periodo 2015-2016. La CICIG informa que en abril de este año (2017) donaron 5 millones más.

En suma, la CICIG intenta fortalecer el Estado y las instituciones de Guatemala, antes que sustituirlas. Fue pensada como instrumento de intervención internacional híbrido, que combina recursos nacionales e internacionales para investigar y perseguir -junto con el Estado- las estructuras criminales que lo han infiltrado y que afectan el proceso de pacificación en el contexto posconflicto. Su presencia y mantenimiento en el país requiere de la anuencia del gobierno de Guatemala y el refrendo bianual de su mandato.

\section{LA CICIG COMO ACTOR AUTODIRIGIDO}

Crisis y recomposición organizacional (2013-2015)

Al momento de escribir este artículo, la CICIG goza de gran credibilidad y respeto dentro y fuera de Guatemala. Sin embargo, vivió un proceso de crisis organizacional muy grave entre 2013 y 2015, cuando la oposición y resistencia del gobierno guatemalteco por su presencia llevó a la renuncia de sus dos primeros comisionados, Carlos Castresana y Francisco Dall'Anese. La llegada del tercer comisionado, Iván Velázquez, estuvo acompañada de fuertes críticas sobre su alto costo e incapacidad para castigar a Efraín Ríos Montt (acusado de genocidio) y/o para juzgar en el país al expresidente Álvaro Portillo (acusado de malversación de fondos) ${ }^{38} \mathrm{El}$ presidente en turno, Otto Pérez Molina se oponía firmemente a la extensión de su mandato (que expiraba en septiembre de

38 CICIG, "Dos años de labores: un compromiso con la justicia", pp. 18-19, en http:/ /www.cicig.org. 
2015) y aconsejaba a la CICIG "transferir capacidades a las instituciones de Guatemala antes de abrir nuevas investigaciones". 39

Es precisamente en este contexto de grave crisis organizacional que la cicig hizo público el caso conocido como "la Línea" (abril 2015), demostrando que integrantes de esta estructura criminal controlaban la administración tributaria y obtenían ganancias millonarias defraudando al Estado. En dicha trama estaban involucrados el presidente en funciones Otto Fernando Pérez Molina y la vicepresidenta de la República, Roxana Baldetti, quienes, ante el escándalo y enojo popular, tendrían que renunciar. ${ }^{40}$

La Línea marcó un antes y un después de la cicig y la catapultó como una organización eficiente, creíble y legítima. A partir de ese momento, todos en Guatemala sabrían que nadie es intocable o, en palabras del comisionado, que "no estamos condenados a vivir en la impunidad". Luego abunda:

Cuando resolvimos con el Ministerio Público presentar el caso La Línea, estábamos en medio de una discusión acerca de la continuidad de la comisión y todo apuntaba a que la Cicig no iba a seguir después de septiembre de 2015. Teníamos la hipótesis de que había una corrupción estructural en Guatemala, con raíces profundas, lo que hace que, de gobierno a gobierno, estructuras corruptas puedan permanecer, sustituirse o mimetizarse transitoriamente. Como último aporte de la Cicig al país, queríamos dejar una radiografía de esa corrupción estructural muy enraizada no sólo en el Estado sino en la sociedad. ${ }^{41}$

39 ICG, "Crutch to Catalyst? The International Commission Against Impunity in Guatemala", reporte 56, 29 de enero de 2016, p. 6, en https://www.crisisgroup.org.

${ }^{40}$ CICIG, "Informe de la Comisión Internacional contra la impunidad en ocasión de su octavo año de labores", s. f., p. 10.

${ }^{41}$ Cf. V. Jaramillo, "Iván Velásquez, comisionado de Cicig: «No estamos condenados a vivir en la impunidad»", EE $N$, 1 de junio de 2016, en http://www.estrategiaynegocios.net. 
El éxito de la organización, derivado de este caso emblemático, da cuenta de un cambio significativo en la cicig. No es un cambio radical en el sentido de que la organización se aparte de sus orígenes y naturaleza, pero sí permite contemplarlo como actor autodirigido, tomando decisiones que afectan claramente su mandato, esto es:

1) a quién perseguir,

2) cómo hacerlo y

3) con qué combinación de recursos.

Así, de su blanco original -los Cuerpos Ilegales y Aparatos Clandestinos de Seguridad (CIACS)-, se abrió paso a un nuevo concepto: las Redes Político-Económicas Ilícitas (RPEI). Con este nuevo concepto, el comisionado Iván Velázquez buscó capturar un fenómeno mucho más amplio, donde se mezclan actores, contextos y dinámicas legales e ilegales, públicas y privadas, formales e informales. A diferencia de los ciacs que ponían el énfasis en estructuras ilegales y del crimen organizado, aquí se visibilizó un fenómeno mucho más complejo, que abarca clientelismo, amiguismo o, como dicen los propios guatemaltecos, toda una cultura del "avivato" y corrupción. Fenómenos mucho más profundos y extendidos en la sociedad y que van desde las campañas políticas a los sistemas de transporte, de las penitenciarías a las aduanas.

Las RPEI se definen como:

la confluencia y/o agrupamiento de individuos que se autoorganizan y cooperan, comunican e informan y poseen intereses comunes y/o finalidades compartidas para la realización de actividades y tareas de carácter político, económico y/o mixtas principalmente ilícitas, aunque colateralmente lícitas. Estas actividades político-económicas llevadas a cabo por agentes (personas físicas y/o jurídicas) con algún grado de informalidad, poseen una serie de características que hacen de la red una entidad informal y/o ilegal que busca y en ocasiones 
logra sustraerse del cumplimiento legal a cargo de las autoridades gubernamentales. ${ }^{42}$

Claramente, la noción de ciacs no se abandona, pero bajo la nueva categoría se genera un cambio en la definición de la problemática del país y se posibilita una actuación mucho más amplia, incluso dentro de estructuras legales o dentro de lo que es el ejercicio cotidiano de la política y la administración pública y que constituían puntos ciegos para la CICIG. Según Luz Adriana Camargo, esta categoría permitió justamente operar mejor el mandato de la organización, ya que se trataba de estructuras que iban más allá de los planteamientos formales del acuerdo, no eran solamente estructuras criminales violentas y armadas que actuaban en detrimento de los derechos humanos, sino que

resultaba difícil detectarlos [a los CIACs] porque parecían legales, actuaban con mecánicas construidas sobre relaciones de actores políticos y económicos legales, donde confluyen intereses privados y públicos en forma compleja y ello se replicaba en cualquier área, como transporte, aduanas... [Estos grupos] realizan actividades ilícitas que pueden parecer lícitas. ${ }^{43}$

Los CIACs, entendidos indistintamente como estructuras criminales (aparatos y/o cuerpos, no jurídicamente definidos, pero que la CICIG precisa como grupos de personas que cometen delitos vinculados con agentes del Estado con capacidad para generar impunidad), ${ }^{44}$ se redefinieron como

una subclase de la criminalidad del poder, configurada materialmente como una Red Político Económica Ilícita (RPEI). [Y este cambio posibilitó] extender la mirada para incluir relacio-

42 CICIG, "Informe de la Comisión Internacional...", p. 6.

43 Entrevista de la autora a la Directora de Investigación de la CICIG, Luz Adriana Camargo, Ciudad de Guatemala, 30 de marzo de 2017.

44 CICIG, "Informe de la Comisión Internacional...", p. 10. 
nes (productoras de estructuras sociales particulares por sí mismas) de empleador-empleado, tomador de decisiones y gestor de intereses, además de asociaciones, empresas, redes y mercados que no están legalmente regulados. Los ciacs conjugan simbióticamente todo el continuum que abarca desde lo formal-legal hasta lo informal-ilegal. Esto permite a los CIACS comportarse de diversos modos: formal-legal, formal tendencial, informal-legal o informal-ilegal, según las circunstancias y sus intereses. ${ }^{45}$

Así, a la pregunta de a quién perseguir, la CICIG amplió y, al mismo tiempo, especificó claramente el espectro de búsqueda y comenzó a identificar fenómenos trasversales, que se mueven entre los ámbitos de lo ilícito y lo legalmente aceptado. En lugar de investigar grupos y cabecillas criminales, comenzó a investigar también funcionarios de alto rango implicados en fenómenos de corrupción administrativa.

Tal como sostiene Luz Adriana Camargo, "una vez que descubrieron que existía este patrón y que la corrupción es la línea transversal, desarrollaron una metodología de trabajo que se enfoca no en perseguir a personas específicas, sino en estudiar temas o fenómenos o denuncias... Descubrimos el abc para todas las operaciones".

En segundo lugar, el cambio en las tareas y metodologías de la cicig quedó plasmado en el Plan de trabajo 2013-2015. Del combate a la impunidad desde las cortes e instituciones de justicia se dio paso al combate a la corrupción endémica develándose estructuras de financiamiento ilícito en las campañas electorales, corrupción administrativa, contrabando y defraudación aduanera, corrupción judicial, narcotráfico y lavado de activos, todo lo cual está centrado en combatir las bases económicas de la impunidad. ${ }^{46}$

Bajo el nuevo concepto operativo, se identificó la corrupción como tema transversal y en consecuencia se esta-

${ }^{45}$ Loc. cit.

${ }^{46}$ CICIG, "Informe de la Comisión Internacional...". 
blecieron cinco fenómenos sujetos a investigación que tienen prioridad:

1) Contrabando y defraudación aduanera;

2) Corrupción judicial;

3) Corrupción administrativa;

4) Financiamiento electoral ilícito;

5) Narcotráfico y lavado de activos.

Con la mira puesta en estas líneas estratégicas, la CICIG desarrolló una cantidad significativa de investigaciones sobre fenómenos de criminalidad compleja, por medio de los cuales se identificaron, procesaron y desarticularon estructuras criminales que han revestido algunas características comunes: $i$ ) ser redes ocultas o clandestinas en su accionar, ii) transitar de lo legal a lo ilegal y de lo formal a lo informal en su accionar, iii) generar poder político para aprovechar recursos económicos del Estado y iv) capacidad de generar impunidad. Así, mientras en el periodo que va del 2007 al 2015, la cicig investigó más de 200 casos y obtuvo órdenes de arresto contra 160 funcionarios públicos en funciones (o retirados) incluyendo expresidentes, ministros del interior y de defensa, miembros prominentes del ejército y de la policía nacional, así como líderes de bandas criminales. ${ }^{47} \mathrm{El}$ éxito de estos procesos se explica en parte por el énfasis de la CICIG en atender los procesos de nominación para la Suprema Corte, Cortes de Apelaciones y Ministerio Público, "nombrando y avergonzando" candidatos que no eran confiables ante la opinión pública, así como promoviendo la creación de Cortes de Alto Riesgo (especializadas y protegidas) para fortalecer el sistema judicial. ${ }^{48}$

En tercer lugar, la sofisticación de los ciacs, entendidos como RPEI, implicó también un cambio organizacional que estuvo dirigido a fortalecer las capacidades de investigación criminal, análisis forense, técnicas de extracción, evidencia

47 Carlos Castresana, art. cit., p. 69.

48 Ibid., p. 64. 
digital, pruebas técnicas (no tanto testimoniales), etcétera. Por su acceso a información y datos del Estado, mercado y sociedad civil, sin mencionar su propia capacidad para fortalecer dispositivos de contrainteligencia, estos grupos imponen un alto reto en su identificación y protegen sus actividades ilícitas.

En estricto sentido, el cambio organizacional se caracterizó por la simplificación y especificación más clara de su enfoque y método de trabajo. Se pasó de 5 departamentos originales a tres (administración, seguridad e investigación), con la intención de "fortalecer los procesos de investigación criminal, dotar de mayor agilidad las investigaciones y mejorar el avance de la metodología de contexto". ${ }^{49}$ Además de enunciar medidas y propósitos, la directora de investigación de la CICIG afirma que hoy día ésta

cuenta con una estructura altamente especializada en corrupción desde el punto de vista de investigación criminal (que no criminalística) y sus casos se estructuran más con base en evidencia técnica que testimonial... Trabajan con una metodología de análisis de contextos (focalizada) e investigan fenómenos, no personas; temas, no denuncias. ${ }^{50}$

Asimismo, reciben entrenamiento, apoyo y equipo específico de especialistas de otros países como, por ejemplo, fiscales colombianos para protección de testigos o fiscales suizos e italianos para investigación financiera.

Todos estos cambios, en su blanco, metodología y estructura organizacional, impulsaron también, según Camargo, nuevas relaciones fuera de la CICIG, tanto con el gobierno, específicamente la Fiscalía Especial contra la Impunidad (FECI) de Guatemala, que se vio fortalecida, ${ }^{51}$ como con la sociedad civil de Guatemala, que ve en la CICIG un actor cla-

49 Véase supra nota 43.

${ }^{50}$ Loc. cit.

${ }^{51}$ Loc. cit. 
ve en la lucha contra la corrupción e impunidad. La sociedad civil es "la mancuerna indispensable de la cicig en el país; sin su apoyo, mediante redes sociales, manifestaciones públicas y cuestionamiento político a sus gobernantes, la CICIG no estaría en condiciones de seguir en el país", ${ }^{52}$ concluye la directora.

\section{Explicaciones teóricas del cambio en la interpretación del mandato}

El proceso de entrevista con los altos dirigentes de la CICIG demostró que el argumento neorrealista y neoliberal institucional, ${ }^{53}$ centrado en los intereses y preferencias de los Estados poderosos (o en este caso, los Estados donantes), no se sostiene en una organización que, si bien está financiada completamente por donantes, carece de un cuerpo de gobierno formal donde dichos Estados tomen decisiones. En el acuerdo constitutivo, no se explícita ningún mecanismo de consulta o rendición de cuentas. El comisionado comentó que suele presentar un informe de labores anuales a los embajadores de los países donantes en Guatemala, pero no está obligado a ajustar sus líneas de trabajo, ni a justificar sus decisiones. Si bien se puede pensar que la CICIG es una organización que en muchos sentidos rinde cuentas, no por ello recibe instrucciones.

Los Estados donantes son un componente crítico para la CICIG; son "sus activos acompañantes" y le proveen de apoyo económico (donaciones) y político (respaldo público), pero, en palabras del propio comisionado, "no debemos confundir con involucramiento directo en el trabajo de la Comisión... Los donantes no ejercen ningún tipo de interferencia sobre nuestro trabajo y decisiones... La CICIG no es agencia de ningún gobierno". ${ }^{4}$

${ }^{52}$ Loc. cit.

${ }^{53}$ Mearsheimer, art. cit.; Robert O. Keohane, op. cit.

${ }^{54}$ Véase supra nota 28. 
Con respecto de las Naciones Unidas también se mantiene un alto grado de independencia en cuanto a la toma de decisiones. Aunque es una creación de la onU, el acuerdo constitutivo no señala prácticamente nada en torno a la supervisión del trabajo cotidiano de la organización, es decir no incluye mecanismos de supervisión y/o seguimiento del Agente (como sostendría la teoría Agente-Principal), ni sobre las tareas del comisionado. ${ }^{55} \mathrm{El}$ comisionado es nombrado directamente por el Secretario general de la onu (y en estricto sentido es su único funcionario), pero claramente goza de flexibilidad y autonomía al interior de la organización e incluso está facultado para firmar convenios de colaboración con otros Estados u organizaciones. ${ }^{56}$ Sobre sus funciones y tareas, según declara Velásquez Gómez, "nada está escrito", de allí que tiene una gran flexibilidad y autonomía para $i$ ) integrar su equipo de trabajo; ii) realizar cambios en el organigrama de la organización; iii) diseñar el plan de trabajo y las líneas estratégicas; $i v$ ) añadir nuevas tareas a la organización y v) realizar informes temáticos. Es esta flexibilidad en su labor cotidiana lo que le permite explotar su experiencia e iniciativa. Gracias a ello pudo definir un nuevo concepto operativo y nuevas agendas de investigación o, puesto de otra manera, ejercer un fuerte liderazgo dentro la organización. ${ }^{57}$

Lo que sí constituye una restricción externa muy significativa por parte de un Estado sobre la CICIG es el hecho de que su mandato debe renovarse cada dos años ante Naciones Unidas a solicitud del gobierno guatemalteco, es decir que el gobierno de Guatemala es quien debe solicitar su permanencia y extensión en el país. ${ }^{58}$ Hasta ahora el mandato se

55 El Comisionado está obligado a entregar un informe anual de labores al Secretario general de la onu en Nueva York.

${ }^{56}$ CICIG, "Acuerdo entre la Organización de las Naciones Unidas y el Gobierno de Guatemala...”.

${ }^{57}$ Más adelante se precisará este aspecto del liderazgo organizacional.

58 El mandato de la CICIG se ha renovado, desde 2007, por periodos de dos años. El 18 de abril de 2016, el presidente de Guatemala, Jimmy 
ha renovado cuatro veces y se encuentra vigente hasta 2019, pero la renovación del mandato es todo un tema y, para lograrlo, es fundamental el respaldo de la sociedad civil. En palabras del comisionado, "sin el apoyo de la sociedad guatemalteca, la CICIG no podría sostenerse en el país". ${ }^{59}$

Entonces, retomadas las posturas teóricas propuestas en este artículo, se pueden observar ciertas lógicas que explican el tipo y la forma de autonomía relativa que una oi como la CICIG ha logrado construir.

De conformidad con la teoría Agente-Principal, la CICIG reaccionó ante un proceso de crisis organizacional y buscó garantizar su propia sobrevivencia. Al hacerlo, redefinió un mandato que era difícil de alcanzar y que limitaba sus posibilidades de acción, es decir se posicionó fuertemente develando esquemas de corrupción administrativa y ya no solamente centrada en esquemas de impunidad y acción violenta. Su objetivo era mostrarse como una institución útil y efectiva.

Y este cambio no fue ni previsto ni controlado por los Principales (donantes y/o Naciones Unidas), pues ninguno de ellos "establece metas o mecanismos de trabajo específicos", 60 según Velásquez Gómez. De hecho, no hay un "contrato" en estricto sentido y los Principales donan de manera voluntaria y sin seguir un esquema o porcentaje específico. De todos los Principales de la organización, el gobierno de Guatemala ha sido quien más ha cuestionado la nueva posición de la CICIG y se han abierto varios frentes de resistencia y oposición, una suerte de diplomacia anticicig, como demuestran los ataques e intentos de expulsión del comisionado Velázquez.

El constructivismo, por su parte, resalta la importancia de la cultura y la sociología organizacional para definir el

\footnotetext{
Morales, solicitó al Secretario general de la ONU prorrogar el mandato de la CICIG hasta 2019. Cf. Centro de Información de las Naciones Unidas, en http:/ / www.cinu.mx/noticias/mundial/guatemala-solicita-a-la-onu-pr.

59 Véase supra nota 28.

${ }^{60}$ Loc. cit.
} 
comportamiento de las organizaciones. ${ }^{61}$ Como sitios de autoridad, como estructuras con capacidad de estructurar conocimientos, las Io i) clasifican el mundo, crean categorías de actores y de acción, ii) fijan significados en el mundo social y iii) articulan y difunden normas, principios y actores alrededor del mundo. Así entonces, la reestructuración de la CICIG en torno a una nueva definición operativa -RPEI-, estaría dando cuenta de la manera en cómo la organización estableció una nueva hipótesis de trabajo y estructuró un nuevo entendimiento para su accionar. Para los altos mandos de la CICIG, una vez que encontraron este patrón de criminalidad, pudieron diseñar un método de trabajo replicable para muy diversas áreas. El nuevo entendimiento consistió en establecer que la corrupción en Guatemala es un fenómeno trasversal, endémico y generalizado. No constituye un fenómeno aislado, sino imbricado en todo el país y, por tanto, la labor de la cicig tendría que ajustarse a esta visión ampliada.

El liderazgo del comisionado y su equipo fue crítico para redefinir el contexto de acción. Fueron ellos quienes dieron una nueva lectura al trabajo de la organización y ampliaron sus funciones y tareas. En entrevista, el comisionado explicó:

el cambio del mandato siguió un proceso interno. Al llegar a Guatemala, comencé a conocer el país y la CICIG... escuchar reclamos ciudadanos y de movimientos sociales; inicié un proceso de conversación con jueces, magistrados, fiscales, diputados, expresidentes, ministros y fundaciones. El mandato no era inmutable, pero el apoyo de la sociedad guatemalteca era fundamental. ${ }^{62}$

Sus cualidades y experiencia personal ayudaron mucho en este proceso. El propio comisionado advirtió que "en Co-

${ }^{61}$ Finnemore y Sikkink, "International Norm Dynamics and Political Change”, International Organization, vol. 52, núm. 4, 1988, pp. 887-917; Hopf, art. cit.; Checkel, art. cit.

${ }^{62}$ Véase supra nota 28. 
lombia había investigado relaciones políticas y paramilitares, y a diferencia de mis predecesores venía de un país lastimado por la violencia donde grupos criminales habían tomado al Estado", 63 pero ello claramente no era suficiente, interpretó, definió y socializó un nuevo entendimiento del problema.

En entrevista, el comisionado resume de este modo la situación:

el Estado de derecho era débil, incapaz de brindar justicia (éste era el fenómeno estructural), y estaba capturado por el crimen organizado (éste era el fenómeno coyuntural), de allí la hipótesis de trabajo... Había que atacar las bases económicas de la corrupción y criminalidad (mandato); atender el fenómeno de corrupción como línea de investigación trasversal, replicable en todos los temas y ámbitos y, para ello, era necesaria una estructura de investigación criminal basada en evidencia técnica... Había que aplicar estrategias similares a la lucha contra la parapolítica, basada en el no divorcio entre investigación y conducción de la investigación con equipos integrados por fiscales. ${ }^{64}$

Luz Adriana Camargo confirma la situación en los siguientes términos:

Cada comisionado rescata aprendizajes. El comisionado [Velázquez] se dio cuenta de que el mandato era demasiado amplio y difícil de desarrollar. Erradicar la impunidad, muy grande, inalcanzable, irrealizable; [además] las investigaciones solamente ayudan a visibilizar, pero no solucionan, se requieren reformas, respaldo ciudadano y erradicar la cultura del avivato..$^{65}$

${ }^{63}$ Loc. cit.

${ }^{64}$ Loc. cit.

65 Véase supra nota 43. 
Fue, pues, el comisionado quien, leyendo el contexto organizacional de la CICIG recuperó su propia experiencia personal en Colombia y estableció una nueva hipótesis de trabajo y una nueva definición del mandato y sus tareas: lo hizo, cuando la organización estaba siendo seriamente cuestionada y en peligro de dejar de existir.

A la par de la bibliografía organizacional que identifica "instancias habitadas" y atiende la manera en cómo las instituciones desarrollan sus propias dinámicas de adaptación, ${ }^{66}$ hay también bibliografía sobre liderazgo organizacional que, sin descuidar la importancia que revisten las cualidades personales, enfatizan la autoridad derivada del cargo. Un debate interesante, que es quizá el más desarrollado hasta ahora, gira en torno al liderazgo del Secretario general de las Naciones Unidas y se expresa como una dicotomía entre el cargo de Secretario o General, esto es entre funcionario administrativo que ejerce el mandato conferido por los Estados (autoridad conferida) y las funciones derivadas de una autoridad activa y poderosa (inherente al cargo). ${ }^{67}$

Según Haack y Kille, tras la estela de Barnett y Finnemore, el liderazgo se ejerce allí donde las ideas requieren redefinición y operacionalidad ${ }^{68}$ y es producto de un proceso cuida-

${ }^{66}$ J. Mahoney y K. Thelen, Explaining Institutional Change: Ambiguity, Agency and Power, Nueva York, Cambridge University Press, 2010.

67 Cf. S. Chesterman (ed.), Secretary or General? The UN Secretary in World Politics, Nueva York, Cambridge University Press, 2007, y, en este mismo libro, D. Kennedy, "Leader, Clerk or Policy Entrepreneur? The Secretary-General in a Complex World", pp. 158-181. También véase K. Kille, From Manager to Visionary: The Secretary-General of the United Nations, Nueva York, Palgrave Macmillan, 2006; I. Johnstone, "The Rol of the UN Secretary-General: The Power of Persuasion Based on Law", Global Governance, vol. 9, núm. 4, 2003, pp. 441-458; I. Claude, "Reflections on the Role of the UN Secretary-General", en B. Rivlin y L. Gordenker (eds.), The Challenging Role of the Secretary-General: Making "The Most Impossible Job in the World" Possible, Westport, CT, Praeger, 1993.

${ }^{68}$ K. Haack y K. Kille, "The UN Secretary-General and Self-Directed Leadership. Development of the Democratic Agenda", en Oestrich (ed.), International Organizations as Self-Directed Actors. A Framework for Analysis, Nueva York-Londres, Routledge, 2012, p. 50. 
doso de negociación entre autoridad delegada y autoridad asumida por el cargo, donde se aprecia la capacidad para generar nuevas formas de acción y entendimiento. ${ }^{69}$

En conclusión, el liderazgo del comisionado se observa en la construcción ideacional de una nueva realidad social (redefiniendo la problemática y el sujeto de intervención), es decir argumentando que el combate a la impunidad demanda también la lucha contra la corrupción administrativa y, en segundo lugar, adaptando a la organización a nuevos procesos y dinámicas de operación concentradas en torno a la identificación de redes complejas de acción delictiva (RPEI). Esto es, el liderazgo organizacional se plasma en la capacidad de generar cambios, agregar tareas, modificar procesos de acción interna y generar nuevas capacidades y ámbitos de acción que fortalecen a la organización misma. Liderazgo entendido como capacidad para interpretar la posición, ventajas y riesgos de la organización y generar cambios necesarios para reorientarla y reposicionarla.

\section{Conclusiones Generales}

Este texto ha tratado de explicar el cambio en la interpretación del mandato de la cicig a partir de un momento crítico y desde una perspectiva endógena. Sostiene que el cambio fue producto de un proceso de decisión y acción autónomas centradas en el comisionado Iván Velázquez y su equipo.

La autonomía organizacional que se observa en este caso no es absoluta. El propio concepto de agencia implica capacidad de acción y decisión, restringidas por un contexto y por otros actores. La clave es comprender que cada organización, incluidas las ors, requieren de enfrentar ese contexto y esas restricciones que son móviles, específicas, situacionales. Sin capacidad de decisión, sin cierta autonomía de acción, las organizaciones difícilmente pueden adaptarse a las

${ }^{69}$ Ibid., p. 36. 
circunstancias cambiantes de su contexto y de su lógica de actuación. Sin duda, habrá ois más atadas a sus estados creadores. Sin embargo, hay diversas ois que han necesitado de construir una agencia más fuerte, enfrentando circunstancias particulares y creando sus propias lógicas de acción.

Para el caso de la CICIG es posible encontrar elementos que explican dicho proceso de agencia, de construcción de actor autodirigido, desde las bases de los estudios de las Relaciones Internacionales que se han apoyado en teorías como la constructivista y de Agente-Principal. Visto así, la documentación estudiada y las entrevistas a los altos mandos de la CICIG parecen indicar que la organización fue capaz de tomar decisiones de manera endógena, atendiendo a sus intereses (de sobrevivencia), reglas y procedimientos (sobre a quién perseguir y cómo hacerlo) y sin intervención directa de los Estados que la crearon o "contrataron". De igual manera, tuvo la capacidad de definir nuevos conceptos, actores y significados de la realidad social, ampliando sus tareas y márgenes de acción, con base en la categoría de RPEI y estructurando sus casos en torno a una definición más amplia de impunidad y corrupción.

El liderazgo del comisionado se entiende como un factor crítico, porque estructuró nuevos entendimientos en una situación de crisis muy fuerte que la organización vivió. Generó una nueva lectura del contexto y otra hipótesis de trabajo, así como nuevas estrategias de acción. Las llamadas Redes Económico Políticas Ilícitas (RPEI) fueron una creación intelectual del comisionado para enfocar las tareas de la organización en torno a la corrupción administrativa, trascendiendo el mandato original que se dirigía al abatimiento del crimen organizado y la impunidad. El cambio posibilitó una nueva metodología de trabajo, así como respuestas mucho más contundentes y efectivas de la organización.

Aunque se puede argumentar con toda razón que, en el fondo, el cambio y rediseño de la CICIG responde a la necesidad de mantenerse viable ante los donantes y creíble ante los guatemaltecos, el propio comisionado afirma que los paí- 
ses donantes no intervinieron en la dirección del cambio ni presentaron resistencia. El eje articulador del cambio, lo propuso y dirigió el comisionado, con base en la propia interpretación del contexto y el problema.

El presente estudio entonces abona al debate sobre las circunstancias y lógicas específicas que llevan a diversas oIs a construir y obtener mayor capacidad de agencia y autonomía. Toda organización requiere enfrentar contextos diversos y específicos para lograr sus objetivos. Diversos grados de autonomía son necesarios para que los propios actores de la organización, los que están enfrentando los retos en la acción, puedan ajustar, interpretar y reconstruir. Las oIs como actores autodirigidos son una posibilidad, tal vez una necesidad por estudiarse y considerarse con mayor seriedad. Comprender las lógicas específicas a través de las cuales diversas oIs pueden requerir y utilizar sus capacidades de agencia implica para la disciplina de las Relaciones Internacionales un reto de comprensión, pero también de diseño, formidable.

\section{Bibliografía}

Ahrne, Göran y Nils Brunsson, Meta-organizations, Cheltenham, UK-Northampton, MA, Edward Elgar Publishing, 2008.

Arce, Alberto, "Pese a las amenazas, la fiscal general de Guatemala, Thelma Aldana, afirma que su trabajo anticorrupción «no ha terminado»", The New York Times, 30 de septiembre de 2016.

Archer, Clive, International Organizations, Londres-Nueva York, Routledge, 2001.

Barnett, Michael y Martha Finnemore, "The Politics, Power and Pathologies of International Organizations", International Organization, vol. 53, núm. 4, 1999, pp. 699-732.

y__ "Defining Refugees and Voluntary Repatriation at the United Nations High Commissioner for Refugees", en Rules for the World. International Organization in Global Politics, Ithaca-Londres, Cornell University Press, 2004, pp. 73-121. 
- y — "Genocide and the Peacekeeping Culture at the United Nations", en Rules for the World. International Organizations in Global Politics, Ithaca-Londres, Cornell University Press, 2004, pp. 121-156.

$-\mathrm{y} \longrightarrow$, Rules for the World: International Organizations and Global Politics, Ithaca-Londres, Cornell University Press, 2004.

Betts, Alexander, "The United Nations High Commissioner for Refugees: Autonomy and Mandate Change", en Joel O. Oestreich (ed.), International Organizations as Self-Directed Actors. A Framework for Analysis, Nueva York-Londres, Routledge, 2012, pp. 119-140.

Bryant, Katherine V., "Agency and Autonomy in International Organizations: Political Control and the Effectiveness of Multilateral Aid", San Francisco, Annual Convention of the American Political Science, 2015.

Castresana, Carlos, "Guatemala. Illegal Entities and the Clandestine Security Apparatus", en Michael Diezdzic (ed.), Criminalized Power Structures. The Overlooked Enemies of Peace, Nueva York, Rowman-Littlefield, 2016.

Checkel, Jeffrey T., "The Constructivism Turn in International Relations Theory", World Politics, vol. 50, núm. 2, pp. 324-348.

Chesterman, Simon (ed.), Secretary or General? The UN Secretary in World Politics, Nueva York, Cambridge University Press, 2007.

Claude, Inis, "Reflections on the Role of the UN Secretary-General”, en Benjamin Rivlin y Leon Gordenker (eds.), The Challenging Role of the Secretary-General: Making "The Most Impossible Job in the World" Possible, Westport, CT, Praeger, 1993.

Collins, Richard y Nigel D. White, International Organizations and the Idea of Autonomy. Institutional Independence in the Legal Order, Londres-Nueva York, Routledge, 2011.

Cox, Robert W. y Harold K. Jacobson, The Anatomy of Influence. Decision Making in International Organizations, New Haven-Londres, Yale University Press 1973.

D’Aspremount, Jean, “The Multifaceted Concept to of Autonomy of International Organizations and International Legal Discourse", en R. Collins y N. D. White, International Organizations and The Idea of Autonomy, Londres, Routledge, 2011. 
Dallaire, Roméo, Shake Hands with the Devil. The Failure of Humanitary in Rwanda, Nueva York, Carroll and Graf Publishers, 2003. Diehl, Paul y Brian Frederking (eds.), The Politics of Global Governance: International Organizations in an Interdependent World, Boulder, CO, Lynne Rienner Publishers, 2005.

Dijkzeul, Dennis e Yves Beigbeder, Rethinking International Organizations. Pathology and Promise, Nueva York, Bergahn Books, 2003.

Ellis, David, "The Organizational Turn in International Organizations Theory", Journal of International Organizations Studies, vol. 1, núm.1, 2010, pp. 1-18.

"Entrevista a Iván Velásquez Gómez, comisionado de la CICIG", Ciudad de Guatemala, 30 de marzo de 2017.

"Entrevista a la Directora de Investigación de la CICIG, Luz Adriana Camargo", Ciudad de Guatemala, 30 de marzo de 2017.

Finnemore, Martha y Kathryn Sikkink, "Taking Stock: The Constructivist Research Program in International Relations and Comparative Politics", Annual Review of Political Science, vol. 4, núm.1, 2001, pp. 391-416.

y - , "International Norm Dynamics and Political Change”, International Organization, vol. 52, núm. 4, 1988, pp. 887-917.

García, Jacobo, "Cárcel para tres ministros del expresidente de Guatemala por «regalar» un helicóptero”, El País, 13 de junio de 2016, en http://internacional.elpais.com

Haack, Kirsten y Kent Kille, "The UN Secretary-General and SelfDirected Leadership. Development of the Democratic Agenda”, en Joel Oestrich (ed.), International Organizations as Self-Directed Actors. A Framework for Analysis, Nueva York-Londres, Routledge, 2012.

Hasenclever, Andreas, Peter Mayer y Volker Rittberger, Theories of International Regimes, Cambridge, University Press, 1997.

Hawkins, Darren G., David A. Lake, Daniel L. Nielson y Michael Tierney, "Delegation Under Anarchy: States, International Organizations and Principal-Agent Theory", en D. G. Hawkings, D. A. Lake, D. L. Nielson y M. Tierney (eds), Delegation and Agency in International Organizations, Nueva York, Cambridge University Press, 2004, pp. 3-37. 
-, (eds.), Delegation and Agency in International Organizations,

Nueva York, Cambridge University Press, 2004.

Hodson, Randy, Andrew W. Martin, Steven H. Lopez y Vicent J.

Roscigno, "Rules don't apply: Kafka's insigths on burocracy",

Organization, vol. 22, núm. 2, 2012, pp. 256-278.

Hopf, Ted, "The promise of Constructivism in International Relations Theory", International Security, vol. 23, núm. 1, pp. 171-200.

Hudson, Andrew y Alexandra W. Taylor, "The International Commission against Impunity in Guatemala: A New Model for International Criminal Justice Mechanisms", Journal of International Criminal Justice, vol. 8, núm. 1, 2010, pp. 53-74.

Hurd, Ian, International Organizations, Politics, Law, Practice, Nueva York, Cambridge University Press, 2011.

Jaramillo, Velia, "Iván Velásquez, comisionado de Cicig: «No esta-

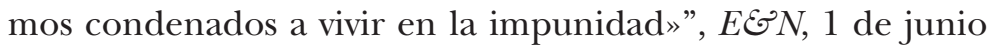
de 2016, en http://www.estrategiaynegocios.net

Johnston, Alastair, "Treating International Institutions and Social Environments", International Studies Quarterly, vol. 45, núm. 4, 2001, pp. 487-515.

Johnstone, Ian, "The Rol of the UN Secretary-General: The Power of Persuasion Based on Law", Global Governance, vol. 9, núm. 4, 2003, pp. 441-458.

Karns, Margaret y Karen Mingst, International Organizations: The Politics and Processes of Global Governance, Boulder, CO, Lynne Rienner Publishers, 2004.

Kennedy, David, "Leader, Clerk or Policy Entrepreneur? The Secretary-General in a Complex World", en Simon Chesterman (ed.), Secretary or General? The UN Secretary in World Politics, Nueva York, Cambridge University Press, 2007, pp. 158-181.

Keohane, Robert O., After Hegemony: Cooperation and Discord in the World Political Economy, Princeton, University Press, 1984.

Kille, Kent, From Manager to Visionary: The Secretary-General of the United Nations, Nueva York, Palgrave Macmillan, 2006.

Lake David y Methew McCubbins, "The Logic of Delegation to International Organizations”, en Darren Hawkins, David Lake, Daniel Nielson y Michael J. Tierney (eds.), Delegation and Agen- 
cy in International Organizations, Nueva York-Cambridge, Palgrave Macmillan, 2006, pp. 241-368.

Mahoney, James y Kathleen Thelen, Explaining Institutional Change: Ambiguity, Agency and Power, Nueva York, Cambridge University Press, 2010.

Mearsheimer, John, "The False Promise of International Institutions", International Security, vol. 19, núm. 3, 1994-95, pp. 5-49.

Moravcsik, Andrew, "Taking Preferences Seriously: A Liberal Theory of International Politics", International Organization, vol. 51, núm. 4, 1997, pp. 513-553.

Nouwen, Sarah, "Hybrid Courts. The Hybrid Category of a New Type of International Crimes Courts", Utrecht Law Review, vol. 2, núm. 2, 2006, en http://www.utrechtlawreview.org

Oestreich, Joel E., "UNICEF and the Implementation of the Convention on the Rights of the Child", Global Governance, vol. 4, núm. 2, 1998, pp. 183-199.

(ed.), International Organizations as Self-Directed Actors. A Framework for Analysis, Nueva York-Londres, Routledge, 2012.

Paullier, Juan, "Iván Velásquez, jefe de la Cicig en Guatemala: «No soy responsable de la caída de Pérez Molina»", BBC Mundo, 4 de septiembre de 2015, en http://www.bbc.com/mundo/noticias

Pollack, Mark, "Delegation, Agency, and Agenda-Setting in the European Community", International Organization, vol. 51, núm. 1, 1997, pp. 99-134.

Reinalda, Bob (ed.), Routledge Handbook of International Organization, Londres-Nueva York, Routledge, 2013.

y Bertjan Verbeek (eds.), Autonomous Policy Making by International Organizations, Nueva York-Londres, Routledge, 1998.

$\mathrm{y} \longrightarrow$, (eds.), Decision Making within International Organizations, pref. de Robert W. Cox, Londres-Nueva York, Routledge, 2004.

Simmons, Beth A. y Lisa Martin, "International Organizations and Institutions", en Walter Carlsnaes, Thomas Risse y Beth A. Simmons (eds.), Handbook of International Relations, Londres, SAGE Publications, 2002, pp. 193-211. 
Trondal, Jarle, Martin Marcussen, Torbjörn Larson y Frode Veggeland, Unpacking International Organizations. The Dynamics of Compound Bureaucracies, Manchester, University Press, 2010.

"Una nueva prórroga a la labor de la CiCiG", El Siglo, 16 de abril de 2016, en http://s21.gt/2016/04/19/una-nueva-prorroga-a-lalabor-la-cicig

Waltz, Kenneth N., Theory of International Politics, Reading, Ma, Addison-Wesley Pub. Co., 1979.

, "Structural Realism after the Cold War", International Security, vol. 25, núm. 1, 2000, pp. 5-41.

Wendt, Alexander, "Anarchy is what States Make of it: The Social Construction of Power Politics", International Organization, vol. 46, núm 2, 1992, pp. 391-425.

\section{INSTRUMENTOS JURÍDICOS, INFORMES Y REPORTES}

"Action Document for Support to the Extended Mandate of the International Commission against Impunity in Guatemala (CICIG)", núm. de CRIS 2016 / 039-237, financiado por Development Cooperation Instrument, en https:/ / ec.europa.eu/euro peaid

"Action Fiche for Project to Support the International Commission against Impunity in Guatemala (CICIG)'s Exit Strategy until September 2015", en http://www.europarl.europa.eu

Boutros-Ghali, Boutros, "Agenda para la paz. Diplomacia preventiva, establecimiento de pazy reconstrucción de paz", A/47/277, S2411, Memoria del Secretario General sobre la labor de la organización, 17 de junio de 1992, en http:/ /www.un.org CICIG: Comisión Internacional Contra la Impunidad en Guatemala, "Acuerdo entre la Organización de las Naciones Unidas y el Gobierno de Guatemala relativo al establecimiento de la Comisión Internacional contra la Impunidad en Guatemala (CICIG)", 12 de diciembre de 2006.

, "Dos años de labores: un compromiso con la justicia", en http://www.cicig.org 
—_ "Informe de la Comisión Internacional contra la impunidad en ocasión de su octavo año de labores", s. f.

Corte de Constitucionalidad, Guatemala, "Opinión consultiva", expediente núm. 1250-2004, 5 de agosto de 2004.

ICG: International Crisis Group, "Crutch to Catalyst? The International Commission Against Impunity in Guatemala", reporte 56, 29 de enero de 2016, en https:/ /www.crisisgroup.org

"Informe de la Comisión Internacional contra la Impunidad en Guatemala con ocasión de su octavo año de labores", en http:/ / www.cicig.org

Misión de Apoyo contra la Impunidad y la Corrupción en Honduras (MACCIH), en http://www.oas.org/es/sap/dsdme/maccih/ new/mision.asp.

Reporte del Secretario General de las Naciones Unidas ante el Consejo de Seguridad, "The Rule of Law and Transitional Justice in Conflict and Posconflict Societies", S/2004/616, 23 de agosto de 2004, pp. 1-24.

_ , "The Rule of Law and Transitional Justice in Conflict and Posconflict Societies”, S/2011/634, 12 de octubre de 2011, pp. $1-19$.

United Nations Office on Drug and Crime, "Global Study on Homicide", 2013, en http://www.unodc.org 
